\title{
PRÁTICAS PEDAGÓGICAS E EDUCAÇÃO INFANTIL DO CAMPO: DESAFIOS, LIMITES E POSSIBILIDADES
}

\author{
Élida Rocha dos Santos ${ }^{1}$; Leomárcia Caffé de Oliveira Uzêda ${ }^{2}$ \\ 1. Bolsista PIBIC/FAPESB, Graduanda em Licenciatura em Pedagogia, Universidade Estadual de Feira de Santana, E-mail: \\ elida.gualberto@yahoo.com \\ 2. Orientador, Professora Doutora do Departamento de Educação, Universidade Estadual de Feira de Santana, vice- \\ Coordenadora do Centro de Estudos e Documentação em Educação (CEDE - UEFS), \\ E-mail: leomarciauzeda@yahoo.com.br
}

PALAVRAS-CHAVE: Educação Infantil do Campo; Educação do campo; Práticas Pedagógicas.

\section{INTRODUÇÃO}

O presente trabalho propõe uma reflexão acerca da Educação Infantil do Campo no Município de Feira de Santana, com base em dois elementos importantes e que precisam de estudos mais específicos, a saber: políticas públicas do município de Feira de Santana voltadas para Educação Infantil do Campo (EIC) e práticas pedagógicas desenvolvidas no contexto da EIC. Esses aspectos ganham sentido se analisarmos as experiências e realidades de escolas localizadas na zona rural do Nordeste, em especial no Semiárido Baiano (BARBOSA, 2012; CAVALCANTE, SILVA E UZÊDA, 2012). O objetivo geral do estudo foi identificar e analisar as práticas pedagógicas de professores que atuam em uma escola pública e exclusiva de Educação Infantil do Campo no Município de Feira de Santana/Bahia. Os objetivos específicos do mesmo foram: analisar das concepções que os professores têm acerca das práticas pedagógicas que desenvolvem junto às crianças de EIC; identificar se os professores contemplam as especificidades e peculiaridades da realidade das crianças do campo nas suas práticas pedagógicas; identificar e analisar se há articulação entre o que é indicado pelos documentos oficiais/nacionais e as práticas realizadas pelos professores junto às crianças.

O estudo é de cunho qualitativo, teve como sujeitos de pesquisa três professoras que atuam em uma escola exclusiva de EIC, as quais foram entrevistadas por adesão voluntária à pesquisa. O trabalho aponta a importância de compreendermos concepções políticopedagógicas que envolvem as ações de professoras da EIC, visto que estas práticas pedagógicas têm implicações na construção identitária das crianças campesinas. (BARBOSA, 2012). Além disso, destaca a carência de discussões sobre esta etapa de ensino no contexto da Educação do Campo (EC), realçando a importância de lutarmos por uma educação contextualizada e que empregue sentidos a vida das crianças no espaço escolar, articulando os conhecimentos da comunidade em que estão inseridos com os que historicamente foram produzidos, que são específicos da Educação Infantil (EI) e que estejam voltados para as vivências, necessidades, culturas e saberes advindos dos sujeitos que trabalham e habitam o campo. (ARROYO, CALDART, MOLINA; 2008)

\section{METODOLOGIA}

A abordagem metodológica adotada no estudo é de natureza qualitativa (ANDRÉ, 2010), seguindo a mesma direção da pesquisa principal a que está ligado o plano de trabalho. Considerando a impossibilidade de acompanhar o universo das instituições públicas de EIC, optou-se dentre os oito distritos rurais localizados na cidade de Feira de Santana, por selecionar um para realização do estudo, e consequentemente, uma instituição que estivesse inserida no mesmo, estabelecendo o critério de que este deveria ter em sua respectiva localidade, uma escola que fosse exclusiva ou que tivesse classes de EIC. O distrito escolhido, a Matinha, abarca vários povoados e fazendas circunvizinhas, o que acaba colocando a instituição de Educação Infantil frente a diversas realidades. Como forma de sistematizar as 
informações obtidas no trabalho de campo, utilizamos os seguintes procedimentos e instrumentos: visitas à escola, realização de entrevista semiestruturada junto a três professoras que se colocaram a disposição para fazer parte da pesquisa. Como apoio a pesquisa foram usadas fontes bibliográficas do acervo existente no Centro de Estudos e de Documentação em Educação, bem como da biblioteca da Universidade Estadual de Feira de Santana, além de buscar em outros diretórios de pesquisa, a fim de oferecer suporte teórico para a fundamentação deste trabalho.

\section{ANÁLISE E DISCUSSÃO DOS RESULTADOS}

Dentre os movimentos específicos em prol da EC, encontra-se a busca pela qualidade da EIC, ou seja, pelo atendimento de crianças que estão na faixa etária entre zero e cinco anos de idade e que vivem no território rural. A luta por uma EIC se institui como um movimento recente, que vem ganhando espaço em cenários públicos e se apresenta como uma necessidade e exigência dos povos do campo, que esperam por uma educação de qualidade para os seus filhos. Mesmo considerando os avanços obtidos ao longo das últimas décadas no país, no que diz respeito EI e ultimamente EIC, ainda precisamos de investimento em políticas que contemplem as infâncias do campo, bem como outras ações ligadas diretamente aos sujeitos, entre eles professoras (es), gestoras (es). (SILVA et al 2012; BARBOSA, 2012).

A partir do exposto, foram coletadas informações através dos depoimentos de professoras da EIC, que permitem uma visão contextualizada da realidade investigada e uma compreensão das dimensões do tema em destaque. No universo de seis professoras, conseguimos que três docentes colaborassem voluntariamente, o que resultou em uma contribuição essencial para o entendimento das questões do cotidiano de uma instituição escolar exclusiva de EIC, que atende crianças de três a cinco anos de idade.

Observa-se, a partir dos depoimentos das professoras, que o entendimento que possuem sobre EI, se aproxima do que está posto na Lei de Diretrizes e Bases da Educação Nacional (Lei $N^{\circ}$ 9.394/96), na qual a EI integra a educação básica, sendo a sua primeira etapa e tendo por finalidade o desenvolvimento integral da criança de 0 a 5 anos de idade, seja em seus aspectos físico, psicológico, intelectual e social, complementando a ação da família e da comunidade (BRASIL, 1996). Quanto ao conceito de EIC, fica evidente o desconhecimento sobre o mesmo, pois todas foram unânimes ao afirmar que não conheciam sequer orientações nacionais ou programas que tratassem da temática. As professoras tentam se aproximar deste conceito, exemplificando que nos seus planejamentos e práticas buscam respeitar as necessidades das crianças, mas não se atentaram para outras questões específicas para EIC. Geralmente transpõem em suas aulas o que trazem de suas experiências em escolas da zona urbana.

Contudo, afirmam saber da necessidade e importância de uma maior discussão e aprofundamento na formação continuada que aborde tais aspectos e que sirvam de apoio para terem melhores condições de trabalho e práticas pedagógicas voltadas para as crianças da EIC, como podemos verificar em uma fala de uma das professoras “[...] A gente fala assim Educação Infantil do Campo, mas nem mesmo as escolas estão no campo, trabalham com o campo. Porque a gente teria que trazer para dentro da escola todos os elementos que são do cotidiano dos meninos e na verdade a gente não faz isso. Eu acho que teria que trazer esses elementos deles para dentro da escola, até como base, para daí surgirem os outros conhecimentos."

Tais aspectos evidenciam de algum modo, a negligência ou o silenciamento dos que estão à frente de órgãos governamentais, no que tange a importância que atribuem a EIC e a formação dos profissionais que irão trabalhar com esse público. Desta forma, é notável que essa situação, acaba reverberando nas práticas pedagógicas que professores desenvolvem junto às crianças e pode ser percebido em mais um depoimento de uma das professoras " [...] a 
gente nunca teve um momento de informação para compreender qual é a diferença entre estar na zona rural, na sede, ou numa escola do campo. Nós nunca tivemos esse momento, eu trabalho nessa escola do campo como se eu estivesse trabalhando numa escola de zona rural como eu estive numa escola da sede [...] eu não diferencio muito, o que seria do campo, da sede ou zona rural, porque a gente não teve esse momento de formação para diferenciar isso. "

Ao indagarmos sobre suas práticas e como eram desenvolvidas junto às crianças campesinas, obtivemos respostas distintas, mas que se complementam. Cabe ressaltar que práticas pedagógicas aqui são entendidas como as ações que os professores desenvolvem com as crianças, o seu planejamento pedagógico, a maneira como se relacionam com a formação humana desses sujeitos, o modo que articulam os conteúdos escolares com assuntos ou experiências do cotidiano das crianças, implicando dessa forma, na construção identitária das crianças campesinas.

Notou-se que cada professora analisa a sua prática a partir de um elemento central que é distinto entre elas, em nenhum momento mencionaram que as ações que desenvolvem com as crianças levam em consideração a demarcação do território em que vivem, e que por causa dessa especificidade as suas práticas seriam diferenciadas, como podemos percebe em uma das falas das professoras; "[...] eu procuro despertar neles o ouvir, o escutar, a hora de falar, a importância de a gente respeitar o outro, de você valorizar a sua cultura local, de você valorizar os seus pais, os seus avós, da importância que tem essa comunidade na vida deles, a casa deles. Tanto que no meu planejamento todo ano eu faço uma aula fora da escola [...] trabalhamos com as crianças atividades e propostas que faça com que valorize cada vez o lugar onde nasceu, onde criou a sua cultura". Tal aspecto pode vir a implicar na formação identitária das crianças e na forma como enxergaram o mundo e a sua comunidade. Ou seja, as professoras utilizam os conteúdos específicos da EI, o que é plausível e essencial, porém não estabelecem uma relação íntima com os elementos que fazem parte da sua história, enquanto sujeitos pertencentes de uma comunidade rural. Todavia, essa prática vai de encontro ao que autores afirmam ser necessária a valorização dos conhecimentos da comunidade em que as crianças estão inseridas, bem como seus modos de vida, sua cultura, suas histórias e suas famílias, que respeite os tempos do campo, os modos de convivência, as produções locais (SILVA et al 2012; BARBOSA, 2012).

A pesquisa nos mostra que as professoras, independentemente da escola de EIC que atuam, precisam compreender que a maneira como cada uma vai conceber a EIC, tem grandes implicações na formação humana, cultural, social das crianças, ou seja, as práticas pedagógicas que desenvolvem são reflexos dessas concepções, de criança, infância, e EIC, e o que fica explicito nos seus depoimentos é a elevação de um conhecimento, os historicamente construídos, em detrimento de outro, os conhecimentos da comunidade local. Apesar do empenho e dedicação inquestionável das professoras por uma educação de qualidade para as crianças, nota-se que são ações isoladas que cada docente desenvolve levando em consideração os aspectos que elencam ser mais pertinentes para trabalhar com as crianças.

\section{CONSIDERAÇÕES FINAIS}

A EIC se constitui um espaço essencial e indispensável para o desenvolvimento integral das crianças oriundas do território rural. A partir das lutas pelo seu reconhecimento e dos contínuos embates em prol da sua consolidação, houve uma mudança considerável no panorama educacional com relação ao atendimento às populações do campo em idade escolar correspondente à EI. Contudo, pensar em EIC, é ter que considerar as suas particularidades e as especificidades, atentando para todos os aspectos que estão a sua volta e que as lhes constituem. É preciso formar professores cujas práticas pedagógicas estejam em consonância com as necessidades formativas das crianças que vivem no campo. Percebe-se que é paulatinamente retirado o direito dessas crianças em receber uma educação de qualidade. A 
EIC ainda não é vista como prioridade, pelos governantes e em alguns casos, pelos próprios profissionais da área.

Todavia, os professores que trabalham com a EIC precisam cuidar e empregar a devida importância que é necessária às suas práticas pedagógicas. $\mathrm{O}$ fato de não termos determinados conhecimento, pode nos levar ao comodismo e a aceitar as coisas como estão postas, sem resistirmos as mesmas. Ou seja, por falta de um conhecimento especifico sobe EIC podemos exercer uma prática urbanocêntrica, uma transposição didática do modelo de EI da cidade, desconsiderando peculiaridades dos sujeitos que habitam no campo, o que por sua vez se traduz em uma prática descontextualizada. Porém, é preciso superar essa visão e práticas. É preciso pensar uma prática transformadora que auxilie no fortalecimento de uma identidade campesina e emancipatória.

\section{REFERÊNCIAS}

ANDRÉ, M. Etnografia da Prática escolar. Campinas, SP: Papirus, $17^{\circ}$ Ed, 2010.

ARROYO, Miguel, Miguel Gonzales; CALDART, Roseli S.; MOLINA, Monica Castagna (Orgs). Por uma educação do campo. 3. Ed- Petrópolis, RJ: Vozes, 2008.

BARBOSA, M. C. S, BARBOSA, Maria Carmem Silveira et.al. (Orgs.). Oferta e demanda da Educação Infantil no campo. Porto Alegre: Evangraf, 2012. Disponível em:

$<$ http://portal.mec.gov.br/index.php?option=com_content $\&$ view=article\&id=12579\%3Aeduc acao-infantil\&Itemid=859>. Acessado em: 15. Jul. 2017

BRASIL. Lei n. 9.394 de 20 de dezembro de 1996. Estabelece as Diretrizes e Bases da Educação. Disponível em: <http://www.planalto.gov.br/ccivil_03/leis/L9394.htm>. Acessado em 28 de jul. 2017.

. MEC/CNE/CEB. Resolução $N^{o} 1$, de 3 de abril de 2002. Institui as Diretrizes Operacionais para a Educação Básica nas Escolas do Campo. Disponível em:

<http://portal.mec.gov.br/cne/arquivos/pdf/CEB012002.pdf>. Acessado em 28 de jul. 2017.

CAVALCANTE, Ludmila Oliveira Holanda, SILVA, Antonia, UZÊDA, Leomárcia c. de O. A escola da criança do campo: reflexões e questões para as políticas públicas no semi-árido baiano. In. Anais do III GRUPECI - Seminário de Grupos de Pesquisa sobre crianças e infâncias: Políticas e desafios na produção da pesquisa -. Aracaju, Universidade federal de Sergipe, setembro de 2012.

SILVA, A. P. S da; PASUCH, J.; SILVA, J. B. da. Educação Infantil do Campo. 1.ed. São Paulo: Cortez, p.271, 2012. 